\title{
Libraries and Google Co-op
}

\begin{abstract}
Google has recently introduced Google Co-op, a platform, which is comprised of three different tools: custom search engine, subscribed links and topics. The custom search engine and subscribed links features of Google Co-op are being used successfully by a variety of different businesses and libraries to help harness the power and size of the Web. Other organizations are contributing to specific search areas designed by Google using the topics feature. By examining the ways that such organizations are using Google Co-op and by demonstrating how to use custom search engines and topics, we will draw some conclusions about the potential usefulness of Google Co-op’s features for libraries.
\end{abstract}

Keywords: libraries, Web 2.0, custom search engines, Google Co-op, subscribed links, niche search, custom search engines, information literacy, Google Marker, Google Refinements

\section{Author Information}

Dawn Bassett, [BA, MLIS] Manager of Content and Information Services. Vancouver Aquarium Marine Science Centre PO Box 3232 Vancouver, BC V6B 3X8

Email: dbassett69@gmail.com

Maha Kumaran, [M.A., MLIS] Adult/Young Adult Librarian.

Saskatoon Public Library, Saskatoon, SK S7H 5J9

Email: maha_kumaran@yahoo.ca 


\section{Introduction}

Recently, social book marking sites such as Del.icio.us, and other Web phenomena such as blogs, wikis, podcasts, and RSS feeds have emerged as tools in the growing area of online communities. These applications are often collectively referred to as Web 2.0, which some library professionals believe is helping the Internet evolve into a more collaborative and interactive space (Abrams 2005, Barsky 2006, Boulos and Wheeler 2007). Web 2.0 applications appear to be very popular with Internet users. According to The Pew Internet and American Life Project, 28\% of “online Americans” have already used the Internet to tag digital media and information (Rainey 2007). The 2007 Digital Future Project found that the use of blogs and the creation and sharing of Web content has doubled in the past three years. These applications are already an important part of the online world, and many libraries are already using blogs and podcasts as part of how they deliver content to their users. However, it is important to continue to experiment with new technologies as they emerge. By doing so, librarians can continue to provide authoritative content, and position themselves to help those who are new to these tools to use them effectively.

Google users can take full advantage of Web 2.0 through a variety of services. They can create blogs using Blogger, share text documents and spreadsheets via Google Docs and Spreadsheets, share photos with Picassa, share notes with Google Notebook, or create a social network through Google Groups. One of Google’s newer features is Google Co-op, a platform that includes subscribed links, custom search engines, and topics. Since it is important for librarians to be aware of the changing landscape of the Internet and trends in searching, it is particularly essential for them to explore custom search engines. This application has a real 
practical purpose, particularly for small or non-profit special libraries, which can use it to develop tools their users can access from any desktop with an Internet connection. With this in mind, we decided to use ourselves as a case study and experiment with Google Co-op’s subscribed links and custom search features, and where applicable, compared them to similar products from other providers. Our objectives were two-fold:

- To provide examples of how librarians can use these tools to develop information literacy skills of their organizations as well as their users

- To provide examples of how librarians can use these tools to promote their collections

\section{Subscribed Links}

Subscribed Links are also known as vertical searches. In vertical marketing, companies market to a certain population segment or industry to be more successful and cost effective. Similarly, vertical search is a way of searching specialized sites that focus on specific audiences or content. In a vertical search, search results "are drawn from content related to a specific industry segment or profession to maximize the relevancy” (Zillmer and Furlong 2005). Consequently, this constrained searching results in unambiguous, relevant searches in a more manageable size instead of offering a billion irrelevant hits. Google already uses this and calls it sponsored links. Through Google Co-op’s subscribed links feature, Internet search providers can use a similar scheme to offer their own vertical searches or use the small directory of providers already available in Google. A good example of this is < http://www.flightstats.com/go/Home/home.do $>$, available from Google Co-op’s Subscribed Links Directory. 
Creating one's own subscribed links is a bit more complicated than it looks, but Google offers tools that a search provider can follow. There are two kinds of subscribed links in Google Co-op: basic subscribed links and dynamic subscribed links. For more on this follow <google.com/Co-op/docs/subscribedlinks/faq.html\#what>.

Librarians and educators can use these subscribed links or create their own custom search engines to help their immediate users. For example, a law librarian or anyone interested in law with no access to expensive law databases could develop a good vertical search by using search engines such as findlaw.com, CanLII, BAILII, or Lawyers.com., etc. Of course not all of the needed information is going to be available from these sites alone, but creating subscribed links is a good start and certainly a much better way of searching than trying on the open Web. Example: using the terms “Divorce Lawyer” in Google retrieved over 3 million results but using the same term in my Law Library search engine created with Google Co-op produced 4 hits. On top were two sponsored links such as lawyers.com and Lawyerdiscovery.com. A small law library or a library with no means of accessing legal information otherwise could create this sitespecific niche search that includes law portals or gateways, law libraries, and legislative and judicial Web sites that have free content for a quicker and efficient search. This technique could be used by a variety of other libraries. School librarians, for example, could create subscribed links and add them to their library Web page. This will ensure that when students do search for information, they have searched the most authentic, trustworthy sites.

Another example is a small library such as the Saskatchewan Literacy Network, a provincial organization that survives solely on funding from provincial and federal governments. Not much money can be spent on updated, new resources each year. In this case subscribed 
links could be composed of literacy networks in Canada and elsewhere, Web sites such as Health Canada, Statistics Canada, and other literacy portals.

\section{Custom Search Engines}

While Google has been extremely successful in making searching for information online easier, finding the right information is more daunting than ever. In The Emerging Opportunity in Vertical Search (2005), Nicole Zillmer and Bill Furlong report that $41.2 \%$ of Internet searchers did not find results directly relevant to their query and 32.5\% found that there were too many results returned. Reasons for this include the fact that casual searchers may be unaware of advanced search features or may not know which keywords are best used to return the most valid results. Once they have a results set, searchers may not be aware which, if any of the thousands of Web sites that are returned to them are current, authoritative, or objective. The custom search engine, however, allows the developer to narrow an enormous amount of information into a more manageable and specific results set providing librarians with another tool they can employ to share search expertise with their users.

Google’s custom search engine feature was launched in October 2006, competing with Rollyo’s searchrolls, Eurekster’s Swicki, and Yahoo’s Search Builder. According to Jennifer Hyman, Product Marketing Manager for Google, over 100,000 custom search engines have been created since the launch of Google Co-op (2007). Several of these search engines were developed by librarians and information professionals. For example, David Rothman has developed the Consumer Health and Patient Education Information Search Engine based on Web sites provided by the National Library of Medicine and the Medical Library Association (2006). There is probably no better place to help consumers with their searching than in the area of consumer health. Rothman's simple search engine allows the searcher to explore Web sites 
specifically chosen by medical search experts. Similar custom search engines have been designed by the American Library Association, which created the Librarian's E-Library (2006), a site that searches 275 sites for information on librarians and librarianship.

To start a custom search engine in Google, users simply sign up and Google guides them through a straightforward set up process. The most complicated part of our sample custom search engine on library job hunting was choosing the web sites that would be included. We wanted to include the most consistently updated and authoritative sites so a bit of background search was done on each of the first ten sites before adding them to the custom search. Once the basic custom search is saved, the developer can use the "control panel," to add or edit new content, invite collaborators, change the look and feel of the search engine, or preview the search results. For the advanced Web content developer, XML can be used to create a more sophisticated search engine. For example, Jump Up, a small business Web portal designed by Intuit, has used a custom search engine to allow visitors to their Web site to search within some top business sites. Not only has Jump up made the Google search engine blend seamlessly into its site, but it has also changed the text colours to match the overall design and style (2007).

Other features that can help users develop their search engine are Refinements and Google Marker. The Refinements feature helps guide users to a particular set of results within their original search set. For example, Garret Hungerford has LISZEN, which searches 600 library blogs (2007). A search in LISZEN for “Intellectual Freedom” provides several pages worth of hits; the initial search can then be refined using the links listed at the top of the search results page. In this case, users can refine the search by individual blogs, special libraries, academic libraries, or school libraries. Users can create their own refinements control panel, or select a pre-defined refinement from a list of "search refinement labels" that are used in Topics 
(the third tool in Google Co-op which we have not covered here). If they choose to use one of these pre-defined labels, searchers who use the search engine will have the added benefit of “seeing relevant sites labeled by others” (Google Existing Search Refinement Labels 2007). Google Marker allows one to add new Web sites to one's custom search while they or their collaborators are searching, thus making updating a custom search engine easy from any desk top. Once their custom search engine is completed, they can either link to it within Google Co-op or copy or paste the code into their Web page or blog. Finally, they can use the statistics feature to track how many queries your search engine has had.

Clearly, creating a custom search engine is relatively easy, but why spend time doing it? As with other Web 2.0 applications, the collaborative nature of custom search engines allows individuals to develop, create, and share their searches. Thus, solo librarians can request help from other librarians, information professionals, or experts in a particular area to contribute to the engine with minimal reliance on over-stressed information systems departments. In many larger library organizations, such as the ALA, librarians have already been participating in this new collaborative atmosphere by sharing information with each other and their users through wikis, blogs and podcasts (Coombs 2007).

Both the LISZEN and ALA's E-Library for Librarians search engines are currently making use of collaborative volunteers this way. This saves both the large and small library money as it costs nothing but time to create the search engine and time can be shared between multiple collaborators. Of course, there will be an initial investment of time to research the topic prior to starting the search engine, but the potential benefit is much greater than the time spent to create it. For many special libraries, a few simple custom search engines in the top subject areas 
of the company can help guide the rest of the company when staff is doing a Google search, thus saving time and frustration for the employee and money for the company.

Saving costs inevitably helps the organization, but collaboration and community building can lead to other benefits for both librarians and their users. Studies on social bookmarking indicate that "collaboration, interactivity and flexibility" lead to "greater participation in learning activities” by both teachers and students (Bolous and Wheeler 2007). Since many librarians are in the position of educating users about technology and search strategies, this is an important potential benefit, particularly for users who are interested in learning about technology and searching, or who are accessing their library remotely. Collaborative technologies, such as social bookmarking, can also lead to a greater understanding of a topic because participants can express different preferences and perspectives (Educause 2005).

Finally, it is important for librarians to help users develop their information literacy skills, and using new technologies such as Google Co-op is an excellent way to do this. A recent study about digital media and learning for young people suggests that participating in an online social environment is creating the need for "new media literacies: a set of cultural competencies and social skills that young people need in the new media landscape” (Jenkins 2006). Jenkins states that "schools as institutions have been slow to react to the emergence of this new participatory culture" and that "schools and after school programs, must devote more attention to fostering these skills which are built on the foundation of traditional literacy, research skills, technical skills, and critical analysis skills taught in the classroom.” Since many libraries offer or are part of those after school programs they need to be on the forefront of this as well, so that they can help young people develop these crucial information and media literacies. For example, librarians could enhance classes on search strategies by having students participate in a 
collaborative custom search engine. Custom search engines could also be used to deliver already trusted resources such as subject guides. Thus users can be directed towards a more authoritative and relevant list of results, which would make search experience less daunting.

While there are many benefits to custom search engines, there are also potential drawbacks. Information professionals warn that because technologies such as wikis, blogs, and social bookmarking reflect "the values" of a particular "community of users, there is a risk of presenting a skewed view of the value of any particular topic” (Boulos and Wheeler 2007). Google Co-op allows the custom search engine creator to decide how to interact with collaborators. This can be limited to only those the user chooses to invite, or can be opened up to the general population as long as they have a g-mail account. Another potential drawback is that results could be too limited, thus leaving out a potentially important piece of information either intentionally or unintentionally. Regardless of this particular drawback, it is important to remember that these applications are additional resources that librarians and information professionals can use to re-package and deliver the same quality of authoritative and balanced content that they normally provide.

\section{Conclusion}

According to a 2006 report from the Pew Internet and American Life Project, as of March of 2006, 42\% of all adults in the US had a high speed Internet connection. This is double the amount since 2005 (Horrigan 2006). This suggests that North American adults are able to do more from their home and work computers, including sharing content and using new applications to get the most out of their Internet experience. As librarians, we know that each individual will have different levels of skill using the Internet regardless of his or her purpose for using it. For those who want to access the Internet to participate socially, we cannot assume that they will 
know how to use these tools. Thus it is important for us to be aware of their potential uses so that we can, as Stephen Abram suggests,

inform them [the users] about and train them in the newest technologies that can have an impact on their success. For those users that can quickly become comfortable using technologies such as wikis, RSS, instant messaging, news aggregators and blogs, we can help them to leverage these in making a difference in reaching their goals. (2005)

In this paper we have demonstrated a few of the practical ways of using Google’s subscribed links and custom search engine features in a library setting, and we have also discussed some reasons why experimenting with new technologies continues to be an important aspect of library service. Using emerging technologies to deliver library content is nothing new.

Librarians have been doing this for years. It is our hope that this paper will inspire librarians and information professionals to continue to participate in this interesting way of searching for information online.

\section{References}

Abram, Stephen. 2005. "Web 2.0, Library 2.0, and Librarian 2.0: Preparing for the 2.0 World.” SyrsiDynix Onesource. 2, no.1. <http://www.imakenews.com/sirsi/e_article000505688.cfm> (accessed March 24, 2007).

American Library Association. 2007. E-Library for Librarians Custom Search Engine. $<$ http://google.com/Co-op/cse?cx=015271347771663724636\%3Acmwvisovdsg > (accessed March 25, 2007).

Coombs, Karen. 2007. "Building a Library Website on the Pillars of Web 2.0.” Computers in Libraries. (January): 16-19.

Barsky, Eugene., and Michelle Purdon. 2006. "Introducing Web 2.0: Social Networking and Social Bookmarking for Health Libraries.” Journal of the Canadian Health Libraries Association. 67: 65-67.

Boulos, Maged N., and Steve Wheeler. 2007. "The Emerging Web 2.0 Social Software: An 
Enabling Suite of Sociable Technologies in Health and Health Care Education.” Health Information and Libraries Journal. 24: 2-23.

Educause. 2005. "7 things you should know about social bookmarking.” 7 Things You Should Know About Series. Educause Learning Initiative. $<$ http://www.educause.edu/7ThingsYouShouldKnowAboutSeries/ > (accessed March 25, 2007).

Google. 2007. Existing Search Refinement Labels - Instructions.

< http://www.google.com/Co-op/docs/cse/labels.html> (accessed March 24, 2007).

Google. 2007. Corporate Information - Company Overview.

<http://www.google.com/corporate/> (accessed March 25, 2007).

Horrigan, John B. 2006. "Home Broadband Adoption 2006: Home broadband adoption is going mainstream and that means user-generated content is coming from all kinds of Internet users." Pew Internet and American Life Project. 28 May 2006.

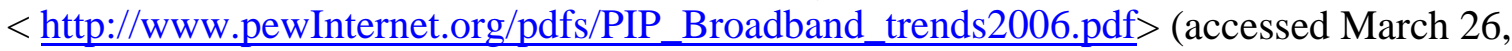
2007).

Hungerford, Garrett. 2007. Liszen: Library and Information Science Search Engine. $<$ http://libraryzen.com/blog/?page_id=61> (accessed March 24, 2007).

Hyman, Jennifer. 2007. “Create a Google Search Engine.” Librarian Central. 22 February 2007. < http://librariancentral.blogspot.com/2007/02/create-google-custom-search-engine.html > (accessed March 26, 2007).

Jenkins, Henry et al. 2006. "Confronting the Challenges of Participatory Culture: Media Education in the $21^{\text {st }}$ Century.” Building the Field of Digital Media and Learning Occasional Papers. 19 October 2006. MacArthur Foundation <

http://www.digitallearning.macfound.org/site/c.enJLKQNlFiG/b.2029245/k.C5DF/Results.htm $>$ (accessed March 26, 2007).

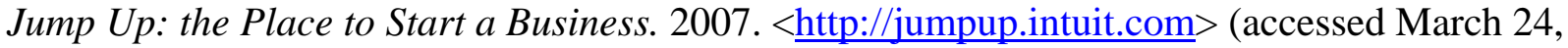
2007).

Rothman, David. 2006. Consumer Health and Patient Information Custom Search Engine. $<$ http://davidrothman.net/consumer-health-and-patient-education-information-search-engine $>$ (accessed March 24, 2007).

Zillmer, Nicole., and Bill Furlong. 2005. The Emerging Opportunity in Vertical Search: A Review of Niche-Oriented Search Engines and Directories. Updated Version. White paperSearchChannel and Slack Barshinger $<$ http://www.slackbarshinger.com/verticalsearch/pdf/0505_vertical_search.pdf $>$ (accessed March 23, 2007). 